\title{
Impact of Emotional Labor on Emotional Exhaustion and Job Satisfaction in Public Sector Organizations
}

\author{
Zafar Iqbal \\ Lecturer, Faculty of Management Sciences \\ University of Kotli Azad Kashmir, Pakistan
}

Asif Mehmood Mirza

MBA, Faculty of Management Sciences

University of Kotli Azad Kashmir, Pakistan

Muhammad Sajid

PhD Scholar, Faculty of Management Sciences

University of Azad Jammu \& Kashmir Muzaffarabad, Pakistan

\author{
Muhammad Adeel (Corresponding author) \\ Lecturer, Department of Business and Management Sciences \\ Mirpur University of Science and technology (MUST), Pakistan \\ E-mail: adeelbashir06@gmail.com
}

Received: Oct. 21, 2018 Accepted: Nov. 6, 2018 Online published: Nov. 20, 2018

doi:10.5296/ijhrs.v8i4.13936 URL: https://doi.org/10.5296/ijhrs.v8i4.13936

\begin{abstract}
Organizationally desired display of emotions is the need of today's organization both in private and public sectors. However, display of emotions or emotional labor and its impact on job satisfaction have been an understudied area in public sector. Therefore, this research examines the impact of emotional labor on emotional exhaustion and job satisfaction. The findings of our study suggest that emotional labor (EL) has a significant positive impact on emotional exhaustion (EE) and job satisfaction (JS) consistent with the earlier research. We
\end{abstract}


have used affective event theory and conservation of resource theory to build our model. Practical and managerial implications of the study are also discussed.

Keywords: emotional labor, emotional exhaustion, job satisfaction, employees

\section{Introduction}

According to Erdogan (2007) over the past few years, exposure to emotions in institutions and organizations has become a major concern, which is critical for service workers, especially for frontline service providers. Negative emotion thinks that failure, fear, anger, hate and pain can work effectively and reduce their work performance (Grandey \& Goldberg 2007). It is impossible to organize feelings for administrators and researchers because they had a big impact on how their employees perform their duties (Xanthopoulou et al., 2017; Diefendorff et al., 2005; Morris \& Feldman 1996).

Emotions are different, so employees need to make efforts to show the emotions that the organization wants, and know that kind of work with emotional work. Emotional Labor (EL) refers to the regulation of emotions and emotional actions within the role of work (Carolyn, Lara, \& Ilaria, 2017; Morris \& Feldman, 1996; Wong, Hui \& Law, 1998). In the public sector organizations, there is a tremendous need to manage emotions and gestures. Therefore, the importance of emotions in the service sector cannot be denied. Emotional work is a term used and applied when interaction between employee and client occurs on a daily basis. It is an interactive process that makes the emotions more visible to the work of employees. On the other hand, depending on the dimensions used, emotional work can also produce negative results (Gabriel, Daniels, Diefendorff, \& Gregura, 2015). Emotions are composed of positive and negative responses of people in their social interactions (Grandey, 2000a; 2003b; Grandy \& Brauburge, 2002; Grandy, Tam \& Brauburge, 2002). EL plays an important role in the organizational outcome in different service sectors. Emotions are common trait of human being, each person far and wide differ one's own with others (Hochschild, 1983; Watson, 1998). While Morris \& Feldman (1996) stated that emotional work has four dimensions (emotional work warning, emotional work frequency, emotional dissonance, kind of emotional labor).

In the literature, Emotional Labor has mainly two dimensions such as deep acting and surface acting (Zeljko et al., 2017; Morris \& Feldman, 1996; Lee \& Ashforth, 1996; Brown et al., 2017). Surface acting is distinguished between true and false emotions. Surface action shows emotions that do not really exist (Grandey, 2000; Grandy, Tam \& Brauburge, 2002; Watson, 1998; Prati et al., 2009). The other dimension is deep acting. Kruml \& Geddes (2000) stated deep acting as the level at which emotions expressed employees are aligned with their actual emotions (Ashforth \& Humphrey, 1993). According to Arnold (2017) the influence of deep acting and surface acting are quite different on the individual. Deep acting involves the true internal modification of negative emotions and tries to really feel the emotion that needs to be displayed (Diefendroff et al., 2005). The frequency of surface acting however, shows correlation with both job satisfaction (JS) and emotional exhaustion EE (Maslash et al., 2001; Rafaeli, 1989). Emotion is the control people with the matter to assign emotions (Chu, 2002). 
According to Hochschild (1983) emotional labor (EL) refers to employees who are required to display emotions. The emotional work of the employees is the salary so it has the exchange value that may differ from whose they feel emotions (Bushra \& Yasir, 2014). More employees need to change their emotional expression, the more they need to strive for their efforts and invest personal resources to change real emotion (Liz, Joyce, \& Mick, 2016). Thus, the results of emotional work will vary depending on the technique used for measuring the employee's emotion (Goldberg \& Grandey, 2007). Emotional labor (EL) and the degree of the workload of emotional labor (EL) (anger, fear, sadness, happiness, disgust and surprise) of emotional work are observed and practiced in most jobs (Robbins, 2011). However, research indicates that job satisfaction has significant impact on display of emotions (Pugliesi, 1999; Rafaeli, 1987).

Job satisfaction also implies that the employees emotional behavior towards their work (Grandey, 2007). Organizations develop training and assistance programs to improve employee loyalty and satisfaction. Workers have been working for a long time, have become more valuable employees. Job satisfaction (JS) is the most important aspect for organization successes (Pugliesi, 1997;Chetna, 2012). Each organization tries to create a workforce satisfied with running the affairs of the organization because the worker is pleased to expand further efforts in performance at work. The overall organization performance depends on organization's employees (Pushpakumari, 2008). Further, when employees are satisfied with their assigned task they perform the job with great effort (Zoub, 2012). Prior literature shows that different consequences are caused by using different emotional labor (EL) strategies, for example, stress, burn out, job satisfaction, job performance and work withdrawal (Grandey, 2007). However, only limited attention has been paid to investigate the relationships between EE, EL and JS in service sector public organizations. Therefore, this study explores and examines the relationship between emotional labor (EL), emotional exhaustion (EE), and job satisfaction (JS) (Aminah, Zoharah, \& Farah, 2017).

EE is a critical problem for the organization; it has a negative effect on the organization as well as employee performance. Hameed (2016) hypothesized that there is a relationship between emotional labor (EL) and job satisfaction. Thus the aim of this paper is to examine the effects of emotional labor (EL), job satisfaction (JS), and emotional exhaustion (EE). In particular, EL, EE and JS providers have different studies, but the public sector is ignored or the literature paid only limited attention (Mastracci et al., 2006; Ghalandari et al., 2012). Ultimately, the more experimental studies were organized on nursing or hotel administration (Kim, 2008), however, this research contributes to the current knowledge about EL by examining public sector organizations. Emotional labor (EL) had deleterious effects on workers performance (Pugliesi, 1999; Grandey, 2000; Hoffmann, 2016). The performance of EL appears to have diverse consequences for workers both negative and positive (Pugliesi, 1999; Kim, 2008; Mastracci, et al., 2006). There is also evidence that the effects of EL are specified by other work condition (Morrison \& Feldman, 1996; Kinman, Wray \& Strange, 2011). Therefore, the present research will answer the fundamental question of what is the impact of emotional labor on job satisfaction and emotional exhaustion among public sector employees. 
To answer the research question and test our theoretical model, we have relied on two fundamental theories, Affective Event Theory (AET) (Weiss \& Cropanzano, 1996) and Conservation of Resource Theory (Hobfoll, 1993). According to Weiss \& Cropanzano (1996), there are some characteristics of the work environment such as job burden that influences the emotions of the employees and their actions. These work actions create disturbing responses and influence behaviors and attitudes related to work such as JS (Aleksandrai et al., 2017). AET depends on employee's job satisfaction and their emotional reactions, which affects all their work. For example, if the work environment contains non-cooperative colleagues, employees task withdrawals, difficult customers, and conflicting goals, it becomes a negative reaction. On the other hand, positive inspection, positive cooperation among colleagues, prospects for personal growth, increased goals orientation, etc., are positive job outcomes, thus increasing JS. However, research also indicates that employee actions for these events are also influenced by their personal nature (Liz, Joyce, \& Mick, 2016).

According to Hobfoll \& Freedy (1993), CRT provides a theoretical explanation of why and when, emotional work with clients contributes to EE. Jobs that involve face to face communication require monitoring of emotions. Similarly, in the process of emotional work, limitation to individual emotional resources can be solved at the same time role functions, such as efforts, completion of work and both types of emotional work. According to the CRT principle, the actual loss of personal resources leads to dissatisfaction and stress, which increases the physical and psychological problems and ultimately the results as the exhaustion of employees (Benjamin et al ., 2017; Hobfoll \& Freedy, 1993).

\section{Literature Review}

\subsection{Emotional Labor (EL)}

According to Caridakis, Asteriadis, \& Karpouzis (2014) body language covers many gestures emotions and attitudes. Previous research shows that there are over 5000 facial expressions that are highlighted, and most phrases are the one that is difficult to hide. Emotions are part of the human personality and few similar emotions can be taught by society and some of them cannot be taught. Socialization and interaction between people always play their part in learning emotions. Other researcher's like Ye \& Packianathan, (2016) described EL as a program of planning, controlling and demonstrating the emotional needs of the organizations. As a result, employees use this feeling for consumers with deep actions, and surface acting. Feelings can be described by the feelings of happy people who see and control them (Housechild, 2010). These feelings or emotions have occurred due to social interaction because we live in normal time to express emotions that may be appropriate and inadequate (Hogan \& Roberts, 1996). Most situations have come into life where employees hinder their true feelings and accept the social feelings. People show an external pressure to express and control their thoughts and expressions. When a person settles his feelings according to social norms, that is known as "emotional work of the mind" (Elizabeth, 2016). At work, employees are expected to display positive emotions particularly in service sector in the firms focusing differentiation based on employees (Brotheridge \& Grandey, 2002). Rasim \& Mustafa (2017) distinguished emotional work and emotional labor such as emotional work is carried out in personal capacity and not paid, however, emotional labor is expected and thus paid. 
Brotheridge \& Grandey (2002) argued that employees sacrifice their natural emotions to be rewarded at workplace by controlling negative emotions and displaying positive. According to Truta (2014) there are three key elements of emotional display at work; firstly, employees want to integrate the word with the public, secondly, open the consumer's attitude and finally give an order to the employer who is able to control the staff. The emotional worker is bound to "try to personally manage the feelings desired by the organization during the interpersonal transaction", to control effort, planning and needs (Grandey, 1998). Studies have examined the relationship between emotional labor (EL) and job satisfaction (JS) (Judge et al., 1997; Cameron et al., 1994). EL increases JS because it can also express emotions and low emotional resources (Ashforth \& Humphrey, 1993). While others conclude that successful management of knowledge-based applications can increase the sense of satisfaction in employment conditions (Wharton, 1999; Pugliesi, 1999). Studies in different occupational groups have sought emotional demands as an important stress factor in many workplaces (Liz, Joyce, \& Mick, 2016). Apart from other professions, teaching is described as a serious emotional activity (Truta, 2014). Personal and other emotions require an efficient control of the emotional state to the desired emotional station. Teachers are expected to protect their students' emotional levels and physical safety. They also need a model of successful emotional management that behaves kindly and avoids any form of insult (Chentna, 2012). It is suggested that the effect of emotional labor depends on job satisfaction (Truta, 2014; Pugliesi, 1999; Xu, 2012). In the business context, there is probably a positive link between emotional labor and job satisfaction. This study puts an end to the potential buffering role of social work in relation to emotional labor, emotional exhaustion and job satisfaction. The research carried out in business and management fields has led to the idea of an environment favorable to work life balance and a combination of useful work related to other positive job outcomes( Arnold, 2017).

According to Kamal et al., (2016) emotion is a difficult psycho physiological practice of personal mood through interaction with external and internal effect. Emotions can be psychological reaction to situation at hand, an expressive reaction to an event and perceiving experience in unusual circumstance (Housechild, 1993). According to Ayhan (2017), there are as many as 5000 thousands reported facial expressions in various cultures. Emotional labor is categorized into two broad categories; deep acting and surface acting (Ashforth \& Humphrey, 1993). In the process of evaluating these two important strategies of EL, several researchers distinguish different types of EL like deep acting and surface acting. Employees who are involved in focusing deep on their inner feelings can express emotions and expectations. There are two ways to do things that are deep, passive and active (Truta, 2014). In deep passive action, the employee really feels the emotion they show. On the other hand, during an active deep action, the employee must change his/her emotional relationship with the situation. When a person uses only expressions of emotion to match emotional criteria with an organization without changing feelings is considered as surfaces acting (Hoffmann, 2016).

According to Jaewon \& Todd (2016) deep acting and surface acting are two techniques that employees can use to control their emotions. Deep acting is an attempt by employees to feel and think about the desired emotions in a unique workplace situation. However, Nilgun (2015) 
is of the view that deep acting is a process of exhibiting a proper facial expression. In addition, to overcome the necessary organizational emotions, deep acting is used as a basic tool (Ashforth \& Humphrey, 1993). The deep acting workers not only treat their emotions, but also modify them to respect the standard emotions of their clients (Grandey, 2003; Ashforth \& Humphrey, 1993). It is important to understand the client's feelings, and those who participate in a deeper commitment also do so. Therefore, deep acting workers can help to sympathize with natural emotions. Fundamentally, there are six general emotions: surprise, disgust, sadness, fear, anger and happiness. It is interesting to note that there are four negative feelings out of six. The anger, fear, sadness, disgust, gives negative emotion and the others one like happiness and surprise give positive emotion (Robbins, 2011).

The surface acting is a category of emotional work in which the verbal, intentional and nonverbal emotions are discussed. Surface acting is keeping the considered emotions unchanged while changing the expressed behavior. EL is associated with stress as workers and employees comprises of fake emotions and acting. Additionally, in the sub category of surface acting, employees and workers are pre-occupied already with job responsibilities and roles while on contrary, more expectations are attached in the role (Elizabeth, 2016). Surface acting reproduces feelings which employees do not really feel their external appearances that show the necessary feelings. In surface acting strategy, individuals modify the outward expression of feeling in the administration of adjusting their internal emotions (Rasim \& Mustafa, 2017).

\subsection{Job Satisfaction (JS)}

The nature of Job Satisfaction (JS) refers to a person's general attitude towards his work. An individual with a high intensity of JS has a positive approach towards his work; someone is not satisfied with his work has negative approach about work (Rutter \& Fielding, 1988). JS is a pleasant emotional exhibition resulting from the positive evaluation of the job (Furnham, et al., 2006. When people talk about the employees' attitude, most often does not mean JS. In fact, both are often used interchangeably. JS has also been defined as the amount of the total positive effect of the work (Griffeth et al., 2000). In some cases, emotional work can bring positive results (Zapf \& Holz, 2006). When the alignment of emotions between emotions and expressions is exposed to "emotional harmony", it shows that there is a fit between the person and the work.

Job satisfaction is an important job attitude of an individual, male or female toward their job. It is the degree to which an individual likes or dislikes the assigned job. Job satisfaction is a complex phenomenon and is a result of an assessment of number of job elements (Ismail, Iqbal \& Adeel, 2018; Hanudin, 2016). Factors that are used to determine JS of peoples at work include financial benefits, employee relations, work environment and role clarity (Yeong \& Kyoung, 2015). There is strong evidence in the literature that the negative consequences of burning emotional work and job dissatisfaction (Brotheridge \& Grandey, 2002; Maslach,, \& Schaufeli, 1993). Khan (2012) states that low or high psychological stress in wage earning employees can affect their psychological wellbeing. Therefore, job satisfaction is a predominant phenomenon to get employees engaged and to enable them 
exhibiting emotional labor (Brotheridge \& Grandey, 2002). Although, previous research shows that job satisfaction (JS) is a complex phenomenon and extensively studied yet, it requires scholarly attention to understand the underlying relationship of JS and EL in public sector organizations. JS is a result of an assessment of number of job elements (Carolyn \& Lara, 2017). In order to achieve goals in organizations, the most complex issues are the relevant rules, emotion of employees in the workplace. The position of an employee's perception varies greatly between emotional expressions and real work (Pugliesi, 1999; Lee \& Chelladurai, 2017). However, employees encounter with the situational perplexity causing them emotional dissonance (Lewig \& Dollard, 2003). At workplace, employees face conflicting situation with emotions expressed and emotions experienced that is emotional dissonance (Lee \& Chelladurai, 2017; Lazarus, 1991). Emotional dissonance may be different, which may determine the reaction of workers to the workplace. Situational factors are important, but employee perceptions are more important than all others (Lazarus, 1991). Jaewon \& Todd (2016) suggested that emotionally charged [positive emotions] can enhance employees' satisfaction and job commitment that are pertinent to the accomplishment of desired organizational goals and objectives.

Job satisfaction assures the employees what they think about their work (Harari et al., 2018). However, it is believed that real or false feelings about the display of emotional tasks can have a positive or negative impact on performance (Carmeli, et al., 2007; Harari et al., 2018; Hoffmann, 2016). Natural feelings can have a positive impact on performance. The experience of the emotional labor will help to better understand more specific interventions, such as a role to play, which has been examined in past studies (Azeem \& Altalhi, 2015; Hoffmann, 2016; Jaewon \& Todd, 2016). Khan ( 2012) defined JS as a positive emotion stating results from the evaluation of the job. Emotional labor (EL) and job satisfaction (JS) showed inconsistent results (Dormann \& Zapf, 2001. However, some studies have found a positive relationship between emotional labor and job satisfaction (Kim et al., 2017; Kim, 2008). Further empirical studies have also confirmed that a positive relationships with emotional labor and job satisfaction exists (Kaur, 2017; Kim et al, 2017; Erickson, 1991; Lee $\& \mathrm{Ok}, 2012)$. On the basis of literature it is hypothesized that:

\section{H1: Emotional labor has significant (positive) effect on job satisfaction.}

\subsection{Emotional Exhaustion (EE)}

According to Whiting, Donthu \& Baker (2011) Emotional Exhaustion (EE) is an early stage of physical and emotional impairment that is a result of more work in the organization and cause continuous stress. EE is a feeling of being emotionally exhausted by work (Whiting et al., 2011; Gaine \& Jermier, 1983). In general, with the consumption of the resources, stress level increases by taking into consideration the goal accomplishment under the resources remaining. The diminishing of resources ultimately causes stress (Fulgate, Kinicki \& Ashforth 2004; Joeri, 2014). Commitment is the opposite of the emotional exhaustion that is defined as "a positive, satisfying and professional mood, characterized by dedication" and it has been suggested that a strong commitment can defend against the emotional exhaustion (Lages et al., 2018; Martinez, 2017; Dust, et al., 2018). Teachers are in many respects at the 
heart of the community, as they act as educator's role models for students, and colleagues. However, these same activities and responsibilities can make them vulnerable to work-related stress (Joeri, 2014). Work-related burden is a common condition in any occupation, and its effects may vary depending on the evolution of individual and condition. Therefore, it is important to study the momentary changes in real time in these factors and their relationship with experienced EE (Martínez, 2017).

EL is the process of managing emotions and expression to meet the emotional needs of the mind (Lazarus, 1991; Lee \& Chelladurai, 2017; Zapf \& Holz, 2006). Above all, employees expect to regulate their emotions with customers, colleagues and seniors (Dust, et al., 2018), involving, decision-making about expressions, whether they are real or not, and the opposite suppress feelings, but not expressions (Carolyn \& Lara, 2017). There is evidence that EL can affect employees because it often takes a psychological effort to regulate emotions in order to meet professional expectations (Bushra \& Yasir, 2014). Front line service providers with direct interactions with customers need to present their feelings as desired by management and expected by a customer. Chetna (2012) stated that front line service provider's exhibit expressions that are not real but such feelings or expressions are expected of them. Particularly strong relationships have been found between EL and EE (Brotheridg \& Grandey, 2002). It can be argued that emotionally demanding time can take away the sense of personal achievement and increase negativity for oneself and for work (Furnham, et al., 2002). EE is a reliable response to the continuous demands of emotional regulation, but relationships with the other two dimensions of exhaustion (fewer emotions and fewer emotions of personal success) are also possible in the teaching profession. Continued EL can lead teachers to depersonalize them due to their low sympathy and their more insane attitude (Diefendorff, Croyle, \& Gosserand, 2005).

EL as a major component of EE bearing in mind that the worrying for these conditions in a person because it is less stressful than involving body rather than shared emotional distress (Aleksandrai et al., 2017). EE, a core dimension of burnout, is a necessary stress connected reaction with depleted energy to figure related problems caused by excessive psychological and emotional demands that happens throughout individuals' work with employees. Gabriel, Daniels, Diefendorff, \& Gregura,( 2015) have found that EE required to organize quality standards is detrimental to personal prosperity. Especially, emotional work can be emotionally exhausted lack of energy, and lack of emotional resources (Schermuly \& Meyer, 2015). Further, they have explained that when workers are involved in surface act, they may suffer emotional dissonance resulting in psychological stress that leads to EE. There was evidence that EL was positive at EE and JS developing effective measures to improve the profession (Dust et al, 2018; Halbesleben \& Bowler, 2007). The present study examines relationships between EL and EE and JS. On the basis of literature it is hypothesized that:

\section{H2: Emotional labor has significant (positive) effect on emotional exhaustion.}


2.4 Theoretical Framework

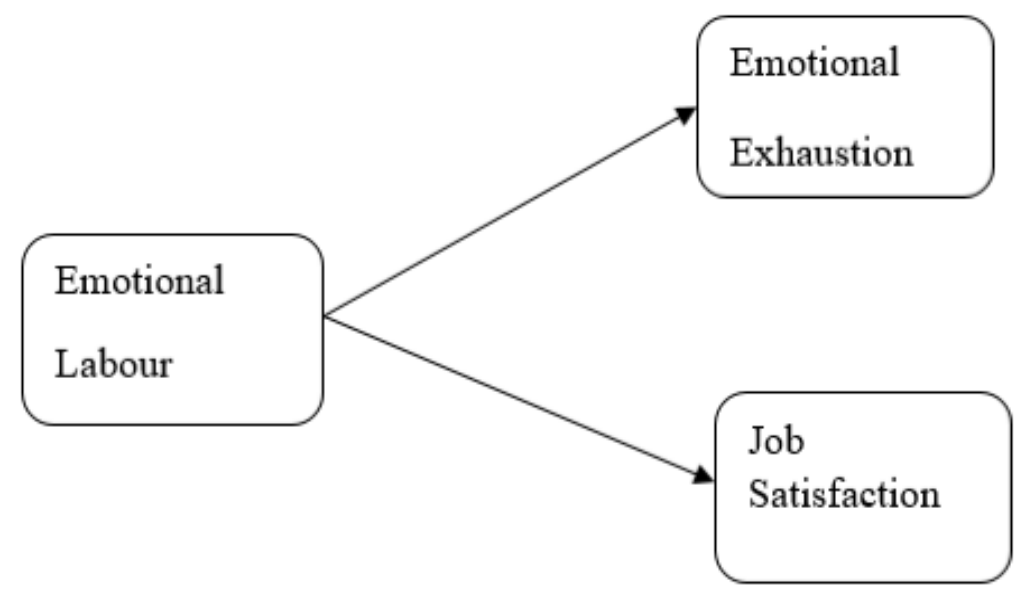

\section{Methodology}

\subsection{Methods}

Data for this study were collected during a study program at post-graduate level. the underlying rational and reason to select faculty members as our study population and sample is that most of the public sector universities employ both male and female in faculty positions and display of emotions to actuate students is of paramount importance (Hansen, \& Mendzheritskaya, 2017). Also, job satisfaction among faculty members in public sector universities has been a question of concern over the past few years (Rosser, 2004). A random sampling technique was used to collected data from targeted population. A total of 435 were questionnaires were distributed among faculty members of the public sector universities in AJK region of Pakistan. Total 227 questionnaires were returned, however, due item non-response, 208 questionnaires were selected for analysis.

\subsection{Measures}

To collect that data, questionnaire was designed in English, as we did not assume any difficulty for faculty members to understand the questionnaire contents and context. We have collected data on 5 points Likert Scale ranging from " $1=$ Agree, 2=Strongly agree, 3=Neutral, 4= Disagree, 5= Strongly disagree". To measure, emotional labor, 06 items scale of Brotheridge \& Lee (1998) was used. The scale's alpha reliability in this study is .712 . Cammann, Fichman, Jenkins \& Klesh's (1979) 05 items scale was used for job satisfaction. The scale's alpha reliability in this study is 0.758 . To measure, emotional exhaustion, 09 items scales of Jackson (2012) was adopted. The scale's alpha reliability in this study is 0.816 . We have used demographic as control variables for our study. 
Table 1. Sample Characteristics

\begin{tabular}{l|l}
\hline Characteristics & Percentage \\
\hline Gender & 76.9 \\
Male & 23.1 \\
Female & \\
\hline Age (Years) & 28.4 \\
$25-30$ & 35.3 \\
$31-35$ & 24.2 \\
$36-40$ & 12.1 \\
41 and above & \\
\hline Qualification & \\
Masters & 58.6 \\
Above Master & 41.4 \\
\hline Experience (Years) & \\
$<=1$ & 20.2 \\
1-2 Years & 5.9 \\
2-3 Years & 34.8 \\
$>3$ Years & 39.1 \\
\hline & \\
\hline Marital Status & \\
Married & 27.5 \\
Unmarried & 72.5 \\
\hline
\end{tabular}

\section{Data Analysis and Results}

In the Public Universities of Azad Jammu and Kashmir, response from 208 teachers was collected, out of which 48 were female and 160 were male.

SPSS 23 software was used to analyze the data. Main tools which were used were reliability analysis, descriptive analysis, correlation analysis and regression analysis. First, reliability, means, standard deviations, and inter-correlations between the variables were computed. Second a series of regression analyses was done by controlling demographic variables.

Table 2. Descriptive Statistics

Total Respondents Mean $\quad$ Standard Deviation
$(N)$

\begin{tabular}{llll}
$E L$ & 208 & 3.44 & .83 \\
$E E$ & 208 & 3.16 & .84 \\
$J S$ & 280 & 3.57 & .88 \\
Valid $N$ & 208 & & \\
\hline
\end{tabular}




\section{Macrothink}

International Journal of Human Resource Studies

ISSN 2162-3058 2018, Vol. 8, No. 4

Table 2 explains the mean EL, EE and JS have the means values of 3.44, 3.16, 3.5 respectively.

Table 3. Correlation

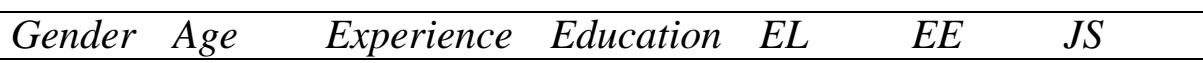

\begin{tabular}{lllllllll} 
Gender & 1 & & & & & & & \\
Age & 0.22 & 1 & & & & & \\
Experience & -.042 & $.496^{* *}$ & 1 & & & & \\
Education & $-.174^{*}$ & -.135 & -.069 & 1 & & & \\
EL & .052 & -.103 & .035 & .127 & 1 & & \\
$E E$ & .001 & -.079 & .022 & $.155^{*}$ & $.402^{* *}$ & 1 & \\
$J S$ & .021 & .071 & -0.55 & .076 & $.489^{* *}$ & $.313^{* *}$ & 1 \\
\hline
\end{tabular}

*. Correlation is significant at the 0.05 level (2-tailed).

**. Correlation is significant at the 0.01 level (2-tailed)

N. 208

$\mathrm{EL}=$ Emotional Labour, EE=Emotional Exhaustion and JS= Job Satisfaction

Table 3 shows that emotional labor (EL) and emotional exhaustion (EE) are significantly and positively correlated with each other $(\mathrm{r}=.402 * *, \mathrm{p}<.01)$ and emotional labor (EL) and job satisfaction (JS) are also significantly and positively correlated with each other $\left(\mathrm{r}=.489^{* *}\right.$, $\mathrm{p}<.01)$.

The regression analysis was conducted which explain the dependence of emotional exhaustion, job satisfaction (criterion) on emotional labor (predictor).

Table 4. Regression Analysis

\begin{tabular}{lllcccccc}
\hline No & $I V$ & $D V$ & Beta & $R$ & $R 2$ & $\Delta \mathrm{R}$ & $F$ & Sig \\
\hline 1 & Emotional labor & Job Satisfaction & .515 & .532 & .283 & .264 & 68.11 & \\
& & & & & & & $* * *$ \\
2 & Emotional labor & Emotional exhaustion & .377 & .437 & .188 & .167 & 31.04 & $* * *$ \\
\hline
\end{tabular}

Correlation is significant at 0.01 level (2-tailed)

$\mathrm{N}=208$

The table above shows overall model summary. Here, $\mathrm{R}$ is the square root of $\mathrm{r}$ square. The value of $\mathrm{R}$ square shows the correlation of dependent and independent variables.

Hypothesis 1

Emotional labor has significant (positive) effect on emotional exhaustion. Our results supported this relationship and found that EL is positively related to JS, as indicated by regression coefficient $(\beta=.515, p<.05)$, supporting.

Hypothesis 2 
Emotional labor has significant (positive) effect on emotional exhaustion. Results supported this relationship and found that EL is also positively related to EE, as indicated by regression coefficient $(\beta=.377, p<.05)$.

Table 5. Summary of Results

\begin{tabular}{ll}
\hline Hypothesis & \multicolumn{1}{c}{ Result } \\
\hline Emotional labor has significant (positive) effect on job satisfaction. & Supported \\
Emotional labor has significant (positive) effect on emotional exhaustion & Supported
\end{tabular}

\section{Conclusion and Recommendations}

This study was conducted to find out the role of emotional labor on emotional exhaustion and job satisfaction in public sector universities of AJ\&K. The current study found a significant positive relationship between emotional labor (EL) and emotional exhaustion (EE), also emotional labor (EL) and job satisfaction (JS). EL is most important factor for the organization as it is the only item that can enhance the performance of employees and achieve the goals and objectives of the organization (Hochschild, 2010)..Results of our study indicated a significant positive relationship between emotional labor and emotional exhaustion and also between emotional labor and job satisfaction. Emotional labor can put employees in a state of going an extra mile to achieve goals and objectives and particularly in teaching profession, teachers place extra importance on working after hours thereby demonstrating emotional labor and maximizing job satisfaction. Thus, it can be concluded that emotional labor is a strong predictor of emotional exhaustion and job satisfaction.

\subsection{Managerial Implications}

The study provides valuable information on the effects of emotional labor on the staff. The search for excellence in services and results of emotional labor required emotional management as a new model. The results of current study recommend the top management of public universities of $A J \& K$ that they should try to motivate their teachers by to display emotional labor to increase their job satisfaction.

\subsection{Limitations and Future Direction}

There is no study without limitation so as this study. The responses were cross-sectional in its nature and data were collected from employees only, therefore, a common method bias might have an impact on results obtained. Further, it is logical to believe that situational factors on a given day and time can affect the responses of the employees. There are many other variables that lead to motivation not only EL. Like emotional intelligent, social support, salaries packages and. organization culture etc. Due to a small sample size the results of study are not generalized to whole population.

\section{References}

Aleksandrai, D., Sanja, B., Zeljko, A., \& Kristina, K. (2017). Emotional exhaustion and job satisfaction of tour guides in rural areas. Emotional exhaustion and job satisfaction of tour 
guides in rural area.

Aminah, A., Zoharah, O., \& Farah, M. R. (2017). Medating role of emotional exaution in the stress. The social sciences, 12(4), 666-673.

Arnold, B. B. (2017, March 30). Emotional labor among employees : a diary study relating strain, emotional labor, and service performanc. The International Journal of Human Resource Management.

Ashforth, B., \& Humphrey, R. H. (1993). Emotional labor in service roles: the influence of identity,. Academy of Management Review, 1(18), 88-115. https://doi.org/10.5465/amr.1993.3997508

Ayhan, K. (2017). Relationship between emotional labor, burnout and turnover intention: a study on hotel business employee. Journal of Business Research, 6(1).

Azeem, S. M., \& Altalhi, H. (2015). Role of Perceived Work-life Balance and Job Satisfaction in. International Journal of Academic Research in Business and Social, 12(5), 185-197.

Benjamin, R., Arnold, B. B., \& Van, G. (2017). Emotional labor among police offiicer: a diary study relating strain, emotional labor, and service performance. The intenational journal of HRM, 852-879.

Bown, E. L., Vesely, C. K., Mahatmya, D., \& Visconti, K. J. (2017). Emotions matter: themoderating role of emotional labour on preschool teacher and children interactions. Early Child Development and Care, 1-15.

Brotheridge, C. M., \& Grandey, A. A. (2002). Emotional labor and burnout: Comparing two perspectives of 'people work'. Journal of Vocational Behavior, 60, 17-39. https://doi.org/10.1006/jvbe.2001.1815

Brotheridge, C. M., \& Lee, R. T. (2002). Testing a conservation of resources model of the dynamics of emotional labor. Journal of Occupational Health Psychology, 7(1), 157-167. https://doi.org/10.1037/1076-8998.7.1.57

Brotheridge, C., \& Lee, R. (1998, August). On the dimensionality of emotional labor: Development and validation of an emotional labor scale. Paper presented at the First Conference on Emotions in Organizational Life, San Diego, CA.

Bushra, A., \& Yasir, A. F. (2014). Impact of Work Life Balance on Job Satisfaction and Organizational Commitment Among University Teachers: A Case Study of University of Gujrat, Pakistan. International journal of multidisciplinary sciences and engineering, 5(9).

Cameron, S. J., Horsburgh, M. E., \& Armstrong-Stassen, M. (1994). Job satisfaction, propensity to leave, and burnout in RNs and RNAs: A multivariate perspective. Canadian Journal of Nursing Administration, 7(3), 43-64.

Cammann, C., \& Fishman, M. (1979, September 21). Scientfic research an acadmia. The Effects of Burnout on Task Performance and Turnover Intention of New Generation of Skilled 
Workers, 5(3).

Carmeli, A., Gershon, G., \& David, A. W. (2007). The Role of Perceived Organizational Performance in Organizational Identification, Adjustment and Job Performance. Journal of Management Studies, 44, 972-92. https://doi.org/10.1111/j.1467-6486.2007.00691.x

Carolyn, H., \& Lara, P. (2017, july 3-5). Stream Proposal for the 10th International Critical Management Studies. Emotions, objects and meaning in organizations.

Chetna, P. (2012). Impact of job satisfaction and organizational commitment on employee loyalty. . International journal of social science \& interdisciplinary research, 1-16.

Chu, K. L. (2002). The Effects of Emotional Labor on Employee Work Outcomes. Unpublished Dissertation, Virginia Polytechnic Institute and State University,

Diefendorff, J. M., Croyle, M. H., \& Gosserand, R. H. (2005). The dimensionality and antecedents of emotional labor strategies. Journal of Vocational Behavior, 66(2), 339-357. ormann, C., \& Zapf, D. (2001). Job satisfaction: A meta-analysis of stabilities. Journal of Organizational Behavior, 22, 483-504.

Diefendorff, M. J., Croyle, H. M., \& Gosserand, H. (2005). The dimensionality and antecedents of emotional labor strategies. Journal of Vocational Behavior, 66, 339-357. https://doi.org/10.1016/j.jvb.2004.02.001

Dust, S. B., Resick, C. J., Margolis, J. A., Mawritz, M. B., \& Greenbaum, R. L. (in Press). Ethical leadership and employee success: Examining the roles of psychological empowerment and emotional exhaustion. The Leadership Quarterly. https://doi.org/10.1016/j.leaqua.2018.02.002

Elizabeth, A. H. (2016). The sociological quarterly. emotions and emotional labor at worker-owned businesses: Deep Acting, Surface Acting, and Genuine Emotions, 152-173.

Erickson, R. J. (1991). When Emotion is the Product: Self Society, and Inauthenticity in a Postmodern World. Unpublished doctoral dissertation, Washington State University, Pullman.

Fulgate, M., Kinicki, A. J., \& Ashforth, B. E. (2004). Employability: A psycho-social construct, its dimensions, and applications. Journal of Vocational Behavior, 65, 14-38. https://doi.org/10.1016/j.jvb.2003.10.005

Furnham, A., Petrides, K. V., Jackson, C. J., \& Cotter, T. (2002). Do personality factors predict job satisfaction?. Personality and individual differences, 33(8), 1325-1342. https://doi.org/10.1016/S0191-8869(02)00016-8

Gabriel, A. S., Daniels, M. A., Diefendorff, J. M., \& Gregura, G. J. (2015, May).Emotional labor actors: a latent profile analysis of emotional labor strategies. Journal of Applied Psychology, 100(3), 863-879. https://doi.org/10.1037/a0037408

Grandey, A. (1998). Emotional labor: A concept and its correlates. Paper presented at the First Conference on Emotions in Organizational Life, San Diego. 
Grandey, A. (2003). When 'the show must go on:' surface and deep acting as determinants of emotional exhaustion and peer-rated service delivery. Academy of Management Journal, 46, 86-96.

Grandey, A. A. (2000). Emotion regulation in the workplace: A new way to conceptualize emotional labor. Journal of Occupational Health Psychology, 5, 95-110. https://doi.org/10.1037/1076-8998.5.1.95

Grandey, A. A. (2000). Emotion regulation in the workplace: a new way to conceptualize emotional labor,. Journal of Occupational Health Psychology, 5(1), 95-110. https://doi.org/10.1037/1076-8998.5.1.95

Grandey, A. A., \& Goldberg, S. L. (2007). Display rules versus display autonomy: Emotion regulation, emotional exhaustion, and task performance in a call center simulation. Journal of Occupational Health Psychology, 12, 301-318. https://doi.org/10.1037/1076-8998.12.3.301

Grandey, A., \& Brauburger, A. (2002). The emotion regulation behind the customer service smile. In R. Lord, \& R. Kanfer (Eds.), Emotion regulation at work (pp. 260-294). San Francisco, CA: Jossey-Bass.

Grandey, A., Tam, A., \& Brauburger, A. (2002). Affective states and traits of young workers: a diary study. Motivation and Emotion, 26, 31-55. https://doi.org/10.1023/A:1015142124306

Griffeth, R. W. et al. (2000) A meta-analysis of antecedents and correlates of employee turnover: update, moderator rests, and research implications for the next millennium, Journal of Management, 26(3), 463-488. https://doi.org/10.1177/014920630002600305

Halbesleben, J. R., \& Bowler, W. M. (2007). Emotional exhaustion and job performance: The mediating role of motivation. Journal of Applied Psychology, 92(1), 93-106. https://doi.org/10.1037/0021-9010.92.1.93

Hameed, F. (2016, September). Impact of personality on adaptive performance with mediating role of emotional labor. testing a mediated moderated model among front-line female hospitality industry employees in pakistan. Human Resource Managemen.

Hansen, M., \& Mendzheritskaya, J. (2017). How University Lecturers' Display of Emotion Affects Students' Emotions, Failure Attributions, and Behavioral Tendencies in Germany, Russia, and the United States. Journal of Cross-Cultural Psychology, 48(5), 734-753. https://doi.org/10.1177/0022022117697845

Hanudin, A. (2016). Why emotion at work matters: examining the influence of emotional labour and emotional intelligence on workplace behaviors among service workers in east Malaysia. Kajian Malaysia, 34(1), 79-105.

Harari, M. B., Thompson, A. H., \& Viswesvaran, C. (2018). Extraversion and job satisfaction: The role of trait bandwidth and moderating effect of status goal attainment. Personality and Individual Differences, 123, 14 -16. https://doi.org/10.1016/j.paid.2017.10.041

Hobfoll., E. S., \& Freedy, J. (1993). A general stress theory applied to burnout. Conservation 
of resources, 115-133.

Hochschild, A. (1990). Ideology and emotion management: a perspective and path for future research. . Research agendas in the sociology of emotions.

Hochschild, A. R. (1983). The Managed Heart, Commercialization of Human Feeling, [Internet], USA. University of California press.

Hochschild, A. R. (2010). Invited Commentary: Can Emotional Labour Be Fun?. International Journal of Work Organisation and Emotion, 3(2), 112-119. https://doi.org/10.1504/IJWOE.2009.030929

Hoffmann, E. A. (2016). Emotions and emotional labour at worker-owned businesses: Deep acting, surface acting and genuine emotions. The Sociological Quarterly, 57(1), 152-173. https://doi.org/10.1111/tsq.12113

Hogan, R., Hogan, J., \& Roberts, B. W. (1996). Personality measurement and employment decisions: Questions and answers. American Psychologist, 51, 469-477. https://doi.org/10.1037/0003-066X.51.5.469

Ismail, S., Iqbal, Z., \& Adeel, M. (2018). Impact of Organizational Justice and Organizational Citizenship Behavior on Employees Performance. International Journal of Human Resource Studies, 8(2), 187-200. https://doi.org/10.5296/ijhrs.v8i2.13070

Jaewon, Y., \& Todd, J. A. (2016). Frontline employee customer-oriented attitude in the presence of job demands and resources: The influence upon deep and surface acting. Journal of Service Research, 19(1), 102-117. https://doi.org/10.1177/1094670515589956

Joeri, K. T. (2014, September 4). Emotional exhaustion and burnout among medical professors. Businessl Education.

Judge, T. A., Locke, E. A., \& Durham, C. C. (1997). The dispositional causes of job satisfaction: A core evaluations approach. Research in Organizational Behavior, 19, 151-188

Kamal, G., Maryam, G., Ghale, J., \& Leala, B. N. (2016). The Effect of Emotional Labor Strategies on Employees Job Performance and Organizational Commitment in Hospital Sector: Moderating Role of Emotional Intelligence in Ira. World Applied Sciences Journa, 319-326.

Kaur, S., \& Malodia, L. (2017). Influence of emotional labour on job satisfaction among employees of private hospitals, a structural equation modelling approach. Journal of Health Management, 19(3), 456-473. https://doi.org/10.1177/0972063417717899

Khan, M. A. (2012). News of foreign sciences. Impact of emotional labor on emotional exhaustion, and moderating role of social support: an empirical study on hospitality industry in Pakistan.

Kim, H. J., Hur, W. M., Moon, T. W., \& Jun, J. K. (2017). Is all support equal? The moderating effects of supervisor, coworker, and organizational support on the link between emotional labor and job performance. BRQ Business Research Quarterly, 20(2), 124-136. 
https://doi.org/10.1016/j.brq.2016.11.002

Kim, H. K. (2008). Hotel service providers' emotional labor: The antecedents and effects on burnout. International Journal of Hospitality Management, 27(2), 151-161. https://doi.org/10.1016/j.ijhm.2007.07.019

Kinman, G., Wray, S., \& Strange, C. (2011). Emotional labour, burnout, and job satisfaction in UK teachers: The role of workplace social support. Educational Psychology, 31, 843- 856. https://doi.org/10.1080/01443410.2011.608650

Kruml, ,. M., \& Geddes, D. (2000). Exploring the dimensions of emotional labor: the heart of Hochschild's work. Management Communication Quarterly, 14(1), 8-49. https://doi.org/10.1177/0893318900141002

Lages, C., Piercy, N. F., Malhotra, N., \& Simões, C. (2018). Understanding the mechanisms of the relationship between shared values and service delivery performance of frontline employees. The International Journal of Human Resource Management. ISSN 1466-4399 (In Press). https://doi.org/10.1080/09585192.2018.1464491

Lazarus, R. (1991). Emotion and adaptation. New York:Oxford University Press.

Lee, J. J., \& Ok, C. (2012). Reducing burnout and enhancing job satisfaction: Critical role of hotel employees' emotional intelligence and emotional labor. International Journal of Hospitality Management, 31(4), 1101-1112. https://doi.org/10.1016/j.ijhm.2012.01.007

Lee, R. T., \& Ashforth, B. E. (1996). A meta-analytic examination of the correlates of the three dimensions of job burnout, Journal of Applied Psychology, 81, 123-33. https://doi.org/10.1037/0021-9010.81.2.123

Lee, Y. H., \& Chelladurai, P. (2017). Emotional intelligence, emotional labor, coach burnout, job satisfaction, and turnover intention in sport leadership. European Sport Management Quarterly, 1-20.

Liz, B., Joyce, D., \& Mick, S. (2016). Emotion, space and society. homson Reuters Journal Citation Reports.

Martínez, Z. F. (2017). National library of management. How does emotional exhaustion influence work stress? Relationships between stressor appraisals, hedonic tone, and fatigue in nurses' daily tasks: A longitudinal cohort study, 43-50.

Maslach, C., \& Schaufeli, W. B. (1993). Historical and conceptual development of burnout. In W. B. Schaufeli, C. Maslach, \& T. Marek (Eds.), Professional burnout: Recent developments in theory and research (pp. 1-16). Washington, DC: Taylor \& Francis.

Mastracci, S. H., Newman, M. A., \& Guy, M. E. (2006). Appraising Emotion Work: Determining Whether Emotional Labor is Valued in Government Jobs. American Review of Public Administration, 36(2), 123-138. https://doi.org/10.1177/0275074005280642

Morris, J. A., \& Feldman, D. C. (1996), The dimensions, antecedents, and consequences ofemotional labor, Academy of Management Journal, 21, 989-1010. 
Prati, L. M., Liu, Y., Perrew_e, P. L., \& Ferris, G. R. (2009) Emotional Intelligence as Moderator of the Surface Acting-Strain Relationship. Journal of Leadership \& Organizational Studies, 15, 368-380. https://doi.org/10.1177/1548051808328518

Pugliesi, K. (1999). The consequences of emotional labor: Effects on work stress, job satisfaction, and well-being. Motivation and Emotion, 23(2), 125-154. https://doi.org/10.1023/A:1021329112679

Pugliesi, K., \& Shook, S. (1997). Gender, jobs, and emotional labor in a complex organization. Social Perspectives on Emotion, 4, 283-316.

Pushpakumari, M. D. (2008). The impact of job satisfaction on job performance. An emperical analysis, 1-17.

Rafaeli, A., \& Sutton, R. I. (1987). Expression of emotion as part of the work role. Academy of Management Review, 12(1), 23-37. https://doi.org/10.5465/amr.1987.4306444

Rafaeli, A., \& Sutton, R. I. (1989). The expression of emotion in organizational life. In L. L. Cummings \& B. M. Staw (Eds.), Research in organizational behavior (Vol. 11, pp. 1-42). Greenwich, CT: JAI.

Rasim, T., \& Mustafa, T. (2017, 2 26). Eductional leadership and management. Positive psychological capital and emotional labor: A study in educational organizations.

Robbins, S. P. (2011). Organizational Behavior. .11th Edition, New Delhi: Prentice-Hall of India Private Limited.

Rosser, V. J. (2004). Faculty members' intentions to leave: A national study on their worklife and satisfaction. Research in higher education, 45(3), 285-309. https://doi.org/10.1023/B:RIHE.0000019591.74425.f1

Rutter, D. R., \& Fielding, P. J. (1988). Sources of occupational stress: An examination of British prison officers. Work and Stress, 2, 292-299. https://doi.org/10.1080/02678378808257490

Schermuly, C. C., \& Meyer, B. (2015). Good relationships at work: The effects of leadermember exchange and team-member exchange on psychological empowerment, emotional exhaustion, and depression. Journal of Organizational Behavior, 37(5). https://doi.org/10.1002/job.2060

Truta, C. (2014). Emotional Labor and Motivation in Teachers. Procedia - Social and Behavioral Sciences, 127, 791-795. https://doi.org/10.1016/j.sbspro.2014.03.356

Watson, D. (1988). Intraindividual and interindividual analyses of positive and negative affect: their relation to health complaints, perceived stress, and daily activities. Journal of Personality and Social Psychology, 54, 1020-1030. https://doi.org/10.1037/0022-3514.54.6.1020

Weiss, H. M., \& Cropanzano, R. (1996). Affective events theory: A theoretical discussion of the structure, causes and consequences of affective experiences at work. In B. M. Staw \& L. 
L. Cummings (Eds.). Research in organizational behavior, 18, 1-74.

Wharton, A. (1999). The psychosocial consequences of emotional labor. . In R. J. Steinberg, \& D. M. Figart (Eds.), Emotional labor in service economy (pp. 38-45), The Annals of the American Academy of Political and Social Science, 561.

Whiting, A., Donthu, N., \& Baker, A. M. (2011). Investigating the immediate and long-term effects of job stressors on frontline service employees. International Journal of Research in Marketing, 28(4), 319-331. https://doi.org/10.1016/j.ijresmar.2011.05.006

Wong, C. S., Hui, C., \& Law, K. S. (1998). A longitudinal study of the job perception-job satisfaction relationship: a test of the three alternative specifications, Journal of Occupational $\begin{array}{llll}\text { and } \quad \text { Organizational } & \text { 127-46. }\end{array}$ https://doi.org/10.1111/j.2044-8325.1998.tb00667.x

Xanthopoulou, D., Baker, A. B., Oerlemans, G. M., \& Koszucka, M. (2017). Need for recovery after emotional labor: Differential effects of daily deep and surface acting.

Xu, Y. X. (2012). Studies on Emotional Labor Strategy of Secondary School Teachers and ItsRelationship with Teaching Efficacy and Job Burnout. Master's Thesis, Wuhan: Hubei University.

Yeong, G. C., \& Kyoung, S. K. (2015). A literature review of emotional labor and emotional Labor Strategies. Universal Journal of Management, 3(7), 283-290.

Zapf, D., \& Holz, M. (2006). On the positive and negative effects of emotion work in organizations. European Journal of Work and Organizational Psychology, 15(1), 128. https://doi.org/10.1080/13594320500412199

Zeljko, A., Aleksandra, D., \& Sanja, B. (2017). Emotional exhaustion and job satisfaction of tour guides in rural areas. Emotional exhaustion and job satisfaction of tour guides in rural areas.

Zoub, M. D. (2012). The shape of the relationship between salary and job satisfaction. A field study. Far East Journal of Psychology and Business, 1-12.

\section{Copyright Disclaimer}

Copyright for this article is retained by the author(s), with first publication rights granted to the journal.

This is an open-access article distributed under the terms and conditions of the Creative Commons Attribution license (http://creativecommons.org/licenses/by/4.0/). 